Children Australia

http://journals.cambridge.org/CHA

Additional services for Children Australia:

Email alerts: Click here

Subscriptions: Click here

Commercial reprints: Click here

Terms of use : $\underline{\text { Click here }}$

\title{
The Halls Creek Way of Residential Child Care: Protecting Children is Everyone's Business
}

Kylie A. Hodgkins, Frances R. Crawford and William R. Budiselik

Children Australia / Volume 38 / Issue 02 / June 2013, pp 61 - 69

DOI: 10.1017/cha.2013.5, Published online: 29 May 2013

Link to this article: http://journals.cambridge.org/abstract S1035077213000059

How to cite this article:

Kylie A. Hodgkins, Frances R. Crawford and William R. Budiselik (2013). The Halls Creek Way of Residential Child Care:

Protecting Children is Everyone's Business. Children Australia, 38, pp 61-69 doi:10.1017/cha.2013.5

Request Permissions : $\underline{\text { Click here }}$ 


\title{
The Halls Creek Way of Residential Child Care: Protecting Children is Everyone's Business
}

\author{
Kylie A. Hodgkins, ${ }^{1}$ Frances R. Crawford, ${ }^{2}$ and William R. Budiselik ${ }^{2}$ \\ 1 West Australian Department for Child Protection \\ 2 Curtin Health Innovation Research Institute
}

\begin{abstract}
This paper describes the collaboration between an Aboriginal community and Western Australia's (WA) Department for Child Protection (DCP) in designing and operating a residential child care facility in a predominantly Aboriginal community. Research literature has established that the effective operation of child protection systems in remote Aboriginal communities requires practitioners and policy-makers to have awareness of local and extra-local cultural, historical and contemporary social factors in nurturing children. This ethnographic case study describes how a newspaper campaign heightened public and professional awareness of child abuse in the town of Halls Creek, in WA's Kimberley region. With its largely Aboriginal population, Halls Creek lacked the infrastructure to accommodate an inflow of regional people. Homelessness, neglect and poverty were widespread. Within a broader government and local response, DCP joined with community leaders to plan out of home care for children. Detailed are the importance and complexities of negotiating between universal standardised models of care and local input. Strategies for building positive relationships with children's family while strengthening both parenting capacity and community acceptance, and use of the facility are identified. Key to success was the development of a collaborative 'third-space' for threading together local and professional child protection knowledge.
\end{abstract}

- Keywords: Aboriginal, remote community, residential care, child protection, ethnography

\section{Introduction}

Indigenous children are almost eight times more likely than other Australian children to be the subject of substantiated complaints of abuse and neglect (Australian Institute of Health and Welfare [AIHW], 2012). The Council of Australian Governments' A National Framework for Protecting Australia's Children 2009-2020 (the Framework) (Council of Australian Governments, 2009) emphasises the importance of a public health model for protecting all children through an interconnected set of universal and targeted welfare policies and strategies. Reducing the over-representation of Indigenous children requires knowledge of interventions appropriate to remote locations. The Framework encourages government and non-government welfare sectors, communities, families and business to collaboratively identify longterm strategies to reduce child abuse and neglect.

Halls Creek is an Aboriginal community striving to take responsibility for its children (Zubrzycki \& Crawford, 2013). This ethnographic case study looks at practices developed there in response to a child protection crisis. Located in the East Kimberley region of WA, 2,873 km from Perth, Halls
Creek has a population fluctuating between 1500 and 2000 residents; $84 \%$ of whom are Aboriginal (Halls Creek Community Strategy, 2008). According to WA's Commissioner for Children (2008), Halls Creek has one of the highest proportions of children and young people in the State $(33.8 \%)$ and within that population the largest proportion of Aboriginal children and young people (over 90\%). There are 65 Aboriginal communities and approximately 28 languages spoken within the region (Department of Employment and Workplace Relations, 2006).

All authors have spent time in Halls Creek and are experienced child protection practitioners. The first author conducted the research as a Bachelor of Social Work honours project with the second author's supervision. The third author was an interested observer throughout the project. Following Bath's (2008) finding that the literature lacks

ADDRESSES FOR CORRESPONDENCE: Dr William Budiselik, School of Occupational Therapy and Social Work, Curtin University GPO Box U1987, Perth, West Australia 6845. Email: W.Budiselik@ curtin.edu.au 
descriptions of such targeted residential care, it seemed important to publish this case study. The people of Halls Creek have worked to protect their children; often having themselves been 'objects' of past harmful welfare policies and practices (Crawford, Dudgeon, \& Briskman, 2007).

The authors connect with Mick Dodson's statement:

I am unable to give comfort to the view that a non-Indigenous person should leave public statements on these questions to Indigenous people alone... The tragic circumstances ... are not alone the business of those who suffer them. (Stanley, Tomison \& Pocock, 2003)

The community's achievements documented here are not 'the' solution to problems at Halls Creek. Rather they are a record of the collaboration between community and government in a climate of despair (Bessarab \& Crawford, 2013).

\section{Setting the scene}

Throughout the 1970s, Kimberley Aboriginal families and communities were moved off their traditional lands. These lands were used as cattle stations and the effect of equal pay reforms was that Aboriginal workers and their families were no longer 'economic' (Crawford, 2011). While some homelands/outstations developed with federal support, Halls Creek received inadequate assistance to develop community services, especially after mission populations (e.g. Balgo) also moved to town (Crawford, 2011). This influx included desert people whose first contact with whites was in the 1940s. Such families were expected to conform to a Western style of living and understand concepts such as social security, classrooms and new law, while dealing with their exposure to alcohol. Many failed to fulfill unrealistic expectations of living a normative Western lifestyle. They encountered sanctions for this. Imprisonment, truancy, alcoholism and homelessness became widespread.

By 2006 a high incidence of foetal alcohol syndrome, community violence, sexual abuse and poor child protection outcomes was evident. A newspaper campaign led by journalist, Steve Pennells, highlighted how the government and bureaucracies had 'failed the people of Halls Creek' ('Halls Creek Reports Lead to Top Award', 2006). In March 2006, Brendon Grylls, leader of the WA National Party, moved a motion in Parliament to acknowledge the crisis at Halls Creek and to establish a select committee to meet with Halls Creek community leaders to address the systemic failures of welfare orientated departments. Grylls' contribution to the debate captured some of the feeling about Halls Creek's relationships with government departments at that time. In part, Grylls said:

The motion seeks to establish a select committee to investigate, with the Halls Creek community leaders, solutions to problems in Halls Creek being advocated by those leaders. This is very important. The Minister for Indigenous Affairs will travel with her departmental heads to Halls Creek tomorrow to discuss with the community its concerns. The community's question for the delegation is: where have those departmental heads been since they have been in the job? They are accused of being asleep at the wheel of their departments. If The West Australian had not reported Steve Pennells' article on Halls Creek, illustrated with coloured pictures, this issue would not be receiving the prominent attention it has attracted. The bureaucratic heads who preside over these departments that have delivered virtually nothing to this community will not be welcomed into it. In fact, last week when the community met to discuss justice issues, community leaders walked out of the meeting in protest at another talkfest. (2006)

By October 2006, the WA government responded with a commitment to build a residential child care facility in Halls Creek. WA politicians supported a call to action in Halls Creek; however they baulked at being accused of creating another 'stolen generation'. This ensured their commitment to any intervention being guided by community consultation ('McHale Pledges Support for Halls Creek Hostel', 2006).

\section{Considerations of the past}

Dr Sue Gordon had led a Commission of Inquiry into the extent of sexual abuse and violence in WA's Aboriginal communities and the quality of responses by state government services (Gordon, Hallahan, \& Henry, 2002). This Inquiry identified child abuse and intergenerational family violence as endemic in WA, and traceable to past policies and practices. Gordon was clear that, regardless of past mistakes, Aboriginal children could not be left in unsafe situations ('Myth of stolen generation is killing Aboriginal children', 2006). Gordon supported the development of a suitable child care facility at Halls Creek.

'Yurag-Man-Gu Taam-Purra', the name selected for the residential child care facility, means 'a good place for kids' and is a phrase from two East Kimberley languages: Djaru and Kitja. The term residential care is defined by the AIHW (2010) as 'a residential building that provides care for young people, aged $12-18$, by rostered staff. This care is short- to medium-term care while safe longer term placement options are arranged (AIHW, 2010). Infants and younger children are not usually considered suitable for placement in residential care because of their high developmental and attachment needs (PeakCare Queensland Inc, 2003). Younger children are also more likely than older children to experience distress when removed from their family because of their heightened need for consistent attachment patterns (PeakCare Queensland Inc, 2003). Children and young people living in residential care are one of the most vulnerable groups in the community requiring specialised support from residential care workers (Tilbury, Osmond, Wilson, \& Clark, 2007). Ideally, residential care workers meet children and young people's health, education, emotional, spiritual and social needs. 
Yurag-Man-Gu Taam-Purru was opened in 2008 aiming to provide such services. Equally important was an aim to embrace the community's voice, needs and vision in the planning and operation of the facility. The facility was designed to comprise two sections: one accommodating up to eight children aged up to six years and the second accommodating up to 12 children aged seven to 18 years. At the time of the research, $90 \%$ of the staff were local Aboriginal people. These community connected staff and DCP collaboratively identified seven operational strategies with input from the community. Arguably consideration of context often happens in practice but fails to be textualised in published description of child care models. This paper aims to detail one grounded example of how context can be usefully integrated with general principles of residential child care.

The effects of abuse, trauma and separation are acknowledged in contemporary residential care (McLean, PriceRobertson, \& Robinson, 2011). Yurag-Man-Gu Taam-Purru strives towards healing and recovery for children using a systemic ecological approach: valuing lived experience to guide the healing process. The challenge is integrating local knowledge and participation within child protection systems bounded by Eurocentric concepts and statutory obligations (Fernandez, 2005). Compounding this is the effect of colonisation resulting in disconnectedness, and minimised Indigenous participation in government decision-making (Campbell, Wunungmurra \& Nyomba, 2005).

Sweeney (cited in Gordon et al., 2002) argues such participation is essential if effective outcomes are to be achieved. This must include collective responsibility by the community to ensure the provision of services is shaped by local knowledge (Higgins \& Butler, 2007). A promising way to achieve this is through creating a 'third space'. Bhabha's (1994) 'third space' concept is used to generate a space of decolonisation where Aboriginal people and others can collaboratively communicate (Dudgeon \& Fielder, 2006). Creating a third space aims to shift dominant Western thinking and create space in-between the colonised and coloniser (Dudgeon \& Fielder, 2006).

\section{Generating a research project through relationship}

Visiting Halls Creek in 2009, the second author met an Aboriginal DCP worker she had worked with in the 1970s. Reflecting on changes in government policies, workers and the community since then, the worker described initiatives that were happening with regard to child protection and mentioned Yurag-Man-Gu Taam-Purru. Later, the senior DCP officer in the region spoke of the need for more practice research focusing on child protection work with Kimberley communities. Separately, Kylie happened to ask if there were any honours projects involving working with Aboriginal people around child protection issues. From these be- ginnings a partnership evolved between the four of us, the University and DCP. Interest in participation was confirmed by other stakeholders.

In line with third space thinking, the research proposal was developed in consultation with DCP Aboriginal Engagement and Coordination and Research Units, and East Kimberley contacts. At all times the aim was to privilege Aboriginal voices. Kylie conducted fieldwork while residing in Halls Creek for 15 weeks. Some interviews were conducted in Perth.

\section{The ethnographic case study}

The research objective was to document how the Halls Creek community and DCP worked together to establish and sustain Yurag-Man-Gu Taam-Purru. Within an ethnographic case study, a focus was on the following sub-objectives:

a. Gathering Halls Creek community members' perspectives about Yurag-Man-Gu Taam-Purru.

b. Documenting the impact of past child protection practices on the local community.

c. Exploring how the community/government partnership has developed.

Ethnography in an Aboriginal context is described as:

Being there, within the time and space of others who guide, advise and inspire me to further embrace performance (in different and contextually specific ways) as a means to interpret, illuminate and advocate a politics of change. (Madison, 2008)

Using this approach, Kylie involved herself in community life and sought historical knowledge alongside evidence of community, media, political and government engagement in the child protection issues of Halls Creek.

Maximising Aboriginal involvement in designing and conducting this research was paramount. Critical race theory guided the methodology. This approach valued local participants' knowledge as embedded within their culture and stressed this in addressing inequitable power dynamics marked by taken-for-granted structural and interpersonal racism (Milner, 2007). Seeking to be conscious of power, subjectivity, racism and culturally appropriate practice was vital to the conduct of the project. Supervision debriefs throughout fieldwork focused on ensuring research practices were open to difference and recognised power dimensions at play. The conduct of fieldwork research required careful mediation between local knowledge, statutory information, observations and between personal, professional and researcher agency. Outcomes depended on the nature of relationships established with participants.

Kylie's immersion in Halls Creek was structured through participant observation, journaling, photography and engaging in informal conversations. These developed an understanding which in-depth interviews furthered. Given ethical considerations interactions with minors occurred 
via participant observation; no children under the age of 18 were interviewed.

\section{In-depth Interview Recruitment}

Participants were purposively selected because of their DCP employment and/or their membership of the Halls Creek community. The eight participants interviewed varied by location, race and professional status. Four participants were local Aboriginal people and four were non-Aboriginal presently or previously employed by DCP. All were involved in the development and running of Yurag-Man-Gu TaamPurru.

\section{What emerged}

The observations, documentation and interviews provided detail on how the facility was conceived, operationalised and maintained. Key DCP figures contributed to the research by responding to themes identified by the researcher and commenting on them in relation to DCP's policies. While the study was limited by time and the small number of people interviewed, all reported on the importance of healing the past, strengthening the capacity of parents, and adopting collaborative and community responsibility for protecting children.

\section{Seven strategies}

At the time of the research Yurag-Man-Gu Taam-Purru's operations were organised around seven strategies. These strategies emerged from collaborative consultations between local people and DCP professionals as to how best protect and nurture children. They are:

1. A commitment to recruiting local staff

2. Maintaining links to culture

3. Staying connected to family

4. Keeping kids strong

5. Learning through play

6. Staff are learning too

7. Celebrating milestones and our identity

The seven strategies are formally documented. The field researcher investigated if, and how, they were incorporated in everyday practices. She researched how the strategies came together in practice to shape outcomes for children and the community.

\section{Enactment}

The seven strategies were observed to frame a consistent and reasoned model of practice professionalising 'the Halls Creek way' of residential care. Because the focus of the research was not on individual children, but rather on how the Halls Creek community and DCP worked together to establish and sustain Yurag-Man-Gu Taam-Purru, not all seven were highlighted in the research. Rather, reflecting on in-depth interviews and ethnographic observations, four of the strategies were identified as central to achieving good outcomes for children and their families. The four with obvious links between each other and to achieving the remaining three strategies were: a commitment to recruiting local staff, maintaining links to culture, staying connected to family and staff are learning too. What the research results showed about the enactment in practice of these strategies is now explored in more detail.

\section{A commitment to recruiting local staff}

The value placed on the strategy to recruit local staff was evident in all in-depth interviews. Achieving this in practice was often difficult but had positive outcomes. Primarily, it upheld the kinship and community connections between the children, staff and families. A local Aboriginal participant described this relationship as feeling like a 'family'. That is 'the Aboriginal way' and provided children with a local 'mentor forever'. Another local participant described her connection to Yurag-Man-Gu Taam-Purru, children and community:

As Indigenous people we are here forever in our own community. And even myself, I've lived away for 12 years at a time but even when I come back, because of .... our strong kinship, our culture, I can just slot back in.

Further benefits identified included:

- Overcoming past welfare practices of oppression and dislocation. A local Aboriginal research participant expressed this as follows:

When families walk in they weren't surrounded by white workers. They were surrounded by people they knew, which immediately overcame some of those initial barriers.

- Operating the facility in a culturally appropriate manner. A local Aboriginal participant perceived past government operations as 'offensive' and 'shameful'.

You need Indigenous too; you need Indigenous people involved to continue the culture, because it's within us ... and that's what's really important - to have someone who understands.

- $\quad$ Providing status, purpose, belonging and fulfilment for members of the local community from their employment in local child protection services.

- Increased social and economic participation in the local community.

- Resources to guide practices and develop policies to meet children's needs, e.g. being able to talk to children in language.

- Strengthening staff and community capabilities. A nonAboriginal participant described professional development as having a 'ripple effect' because those staff share their learning with others in their family and the community. 


\section{Maintaining links to culture}

Culture defines our identity. If Aboriginal children in residential care are denied connections with family and culture they are at greater risk of psychological, social and educational disadvantage. The importance of these connections may not be intuitively understood by non-Aboriginal staff.

Children have a special place within family and community. Where they are born signifies connection to the land and/or sea. It identifies a child's relationships and responsibilities to law and culture and establishes certain obligations and responsibilities according to traditional Aboriginal law. Today, many Aboriginal children are born 'outside' their country. It is their relationship and identity with their language group that gives a child the connection to their country. (Secretariat of National Aboriginal and Islander Child Care, 2008)

Aboriginal children placed in residential care may experience grief, loss, feelings of dispossession and alienation which all diminish the child's capacity to establish a sense of belonging and identity.

Participants acknowledged the importance of children maintaining cultural connections not only as the child's right, but also the community's. These cultural connections are upheld by:

- Employing local staff.

- Permitting, supporting and encouraging parents/family to fulfil the carer role.

- Including parents and other family members on bush excursions and cultural activities.

- $\quad$ Utilising the Halls Creek Language Centre for the children to learn traditional language and to engage with community elders.

- Celebrating and embracing the children's cultural identity by participating in National Aborigines and Islander Observance Committee (NAIDOC) week celebrations. The children accompany staff on hunting trips and help prepare bush tucker.

- Participating in traditional 'smoking' ceremonies to promote spiritual, social and emotional well-being.

A local Aboriginal man discussed the importance of passing on such practices and knowledge to sustain children's cultural identity, preparing them for adulthood. He said:

When they get out of here, they'll know what to do... and what to do to a goanna. So when they get out of here, they've been taught by somebody.

He explained how passing on this knowledge increases children's understanding:
I won't be next to them if they get out of here. They've got to be strong themselves... When they get out of here, they will be back with ... parents, and if their mother is sick, who is going to do those things?

\section{Staying connected to family}

Swain and Atkinson (1999) discuss how colonisation has resulted in generations of children being denied the opportunity to maintain close kinship and cultural connections: 'both the skills and confidence of parents have been damaged, with the result that [Indigenous] children continue to be overrepresented in the child welfare system'. To address this, Connolly (2009) argues residential care practices must strengthen family involvement in the child's care planning process.

WA's child protection legislation, the Children and Community Services Act 2004 (WA), promotes the Aboriginal Child Placement Principle and at section 13 provides Aboriginal parents have the right to self-determination in the following terms:

In the administration of this Act a principle to be observed is that Aboriginal people and Torres Strait Islanders should be allowed to participate in the protection and care of their children with as much self-determination as possible.

Libesman (2007) expands on the concept of selfdetermination in the following way:

Effective child protection requires implementation of principles of self-determination which, in turn, necessitates collaboration between Indigenous communities and organisations and non-Indigenous institutions, including child welfare departments. An Indigenous understanding needs to permeate all aspects of legislation, service design and delivery. While measures such as the inclusion of Indigenous staff in mainstream systems do improve these systems, such improvements are within a framework which is not attuned to addressing the structural or underlying needs of communities. Fundamental improvement requires acknowledging and facilitating community capacity to make and implement policy and programs which address individual and community child protection needs and, more broadly, requirements with respect to Indigenous children's wellbeing... What is necessary is an integrated approach to addressing individual and community trauma, building community capacity with a particular focus on children and families.

Reflecting this, Yurag-Man-Gu Taam-Purru staff embrace their obligation to facilitate contact between parents and children and in collaboration with DCP field officers have developed an 'open-door policy'. The goal is to promote attachment between parents and children. All involved recognise that loss or disruption of the parent/child relationship can impede the child's future development and their capacity to establish and maintain safe relationships (Perry, 2001). Facility staff encourage and support parents to adopt the care role when visiting their children by feeding, bathing and playing with them. Such interactions aim to increase parenting capacity, while upholding kinship connections and 
working towards reunification. As relationships between the staff, community, families and children developed the evolution of the open door policy was described 'as a natural thing. In comparison to DCP's traditional residential care model, this is a distinctive difference.

A local Aboriginal participant explained the open-door policy was initially difficult for the parents to interpret because of past negative experiences of 'old welfare times'. These times were associated with control and mistrust. The open-door policy acknowledges the importance of trust, awareness of cultural needs, and being respectful of parents' motivation to remain connected to their children. A non-Aboriginal participant described the approach as explicitly saying to parents, 'we want to work with you!' It has resulted in staff establishing meaningful relationships with parents. To foster this, further relationship building opportunities were initiated such as weekend barbeques with employees, parents, the children's extended family and community members.

Yurag-Man-Gu Taam-Purru staff often support parents whose children have been assessed as 'failure to thrive' (i.e. low weight for age and delayed achievement of development milestones). The condition is often associated with foetal alcohol syndrome (Kimberley Aboriginal Medical Services Council and WA Country Health Service, 2009). Staff support parents' learning, e.g. feeding techniques. This working alongside parents is facilitated by an independent living unit for parents and other family members to reside on site, thereby remaining connected to their child in a supportive and safe environment. A local Aboriginal participant explained:

We talk about reunification and how can you do that if you don't have an open door policy ... We are talking about them going back. So we need to know that they can come in here and see the kids, give them their love, nurture them while they are sick too, to be here with them, to give them their medication, to put them to bed.

She described establishing these relationships as giving 'responsibility' to parents which helps 'keep up hope'. A nonAboriginal participant commented:

What we did was (both) logical and not logical from my point of view but for the community it is (logical). If we had to have a (care facility) it was a sensible way to do it in terms of not disconnecting kids from families.

\section{Staff are learning too}

Staff at Yurag-Man-Gu Tamm-Purra and in DCP are expected to be active learners in the quest to provide the best possible care for children. The focus in Halls Creek was on moving beyond dichotomising Aboriginal and professional child protection cultures. All involved were expected to be both learners and teachers. This understanding was potentially at odds with information provided by a DCP metropolitan participant who said:
In the past, a lot of staff might have relied on what they did as a parent, so personal experience, whereas in order to professionalise it we all need to be following a particular framework and identified model.

Addressing such tensions has been part of the dialogue of the Halls Creek 'third-space' team. If the practices were to be professionalised and staff skilled and proficient, did they need to be 'templated' to an outside model? A metropolitan based participant said the issue was 'these are not your kids, we know they are (from) your community but they're not your kids, they are traumatised children'.

It was evident the Aboriginal staff interviewed wanted to develop their knowledge and skills and have open discussion about local styles conflicting with DCP's standards. Of course, maintaining such dialogue depends on the commitment of all to the process.

Research observations and participants' narratives indicate present operations have been professionalised. Enactment of the seven strategies has served this purpose and serves as a reference point for further development. A metropolitan DCP participant identified the need for leadership that can 'marry' DCP's policies with contextual needs and local voices. She felt this had happened in the case of Halls Creek and highlighted the importance of responsive and flexible leadership in achieving good outcomes.

The negotiating skills involved in 'doing' such leadership in practice were observed when a local Aboriginal DCP employee was asked to facilitate a presentation at Yurag-Man$\mathrm{Gu}$ Taam-Purru about a new head office adopted model of residential care. The developers of the model were internationally based and would have had no knowledge of Halls Creek and the seven strategies. Throughout the presentation to a local audience of workers and community members the facilitator linked the points covered to their local ongoing task of 'marrying the two together'. She emphasised this new model was in many ways complementary to the seven strategies and would be implemented the 'Halls Creek way'. Holding and working creatively with such tensions is part of effective practice in child protection.

Many local staff have themselves experienced intergenerational grief, loss and community trauma. A participant described engaging with the professional knowledge of child protection as being a process to 'understand ourselves better so we can be teachers for the children'. As a local participant explained there is a need to 'look after our staff so they can provide that healthy care, and wellbeing for the kids: Because it is a full circle kind of thing'. There was a clearly expressed hunger by the staff for access to child protection knowledge.

\section{Challenges}

Yurag-Man-Gu Taam-Purru was described by one participant as being a 'challenge on the ground and in the wider (DCP) system'. Tensions operated between the two systems. 
For instance, the open-door policy contradicted DCP's policies on children not being permitted extensive contact with family on residential care premises. According to a participant Perth-sourced residential care workers often assert on arrival in Halls Creek, 'It needs to be locked down, you've got Aboriginal families coming in here, it's chaotic!' The participant clarified, 'It's not actually chaotic. (We have) practice principles that allow a family to come inside and engage with their kids'.

Yurag-Man-Gu Taam-Purru staff demonstrated the open-door policy could be implemented without compromising the safety of the children, caregivers and staff. When conflict between the two systems surfaced, the manager and local staff detailed the rationale of their practices. Addressing such tensions and documenting local input is what had led to naming the seven strategies in the first instance. The process is dynamic and open to change. The community's commitment to promoting its vision of care and the openness of DCP to hearing this were identified as central to enabling the development of Yurag-Man-Gu TaamPurru.

\section{Importance of relationships}

What has happened in Halls Creek highlights the importance of working together towards a common purpose of benefitting children in care. Connolly (2009) emphasises that good practice in residential care must incorporate a practice framework that integrates research, theory, ethics and experiential knowledge. She draws particular attention to the integration of formal and informal sources of knowledge to effectively guide child protection practices and policies. Drawing on such multiple sources of knowledge led to Yurag-Man-Gu Tamm-Purra's operations being established and sustained according to local values, contexts and needs alongside a DCP framework. Such an achievement will always be a dynamic one requiring ongoing commitment from all parties just as the need for targeted forms of childcare is itself subject to circumstances.

As a participant described, 'as a model for residential care it may not necessarily work in other areas but it showed when you work locally and work with the local community you are in you can make a difference'. Reflecting on this research some guiding principles of practice can be identified. These are in line with Libesman's (2004) argument that the 'one-size fits all' approach will not work across diverse communities. Yurag-Man-Gu Taam-Purru arose from community lobbying, a media campaign, politicians' voices, practitioners' knowledge and the community's ownership of its children. This was a case of a response being initiated, implemented and evaluated at a local level, according to the community's needs and culture. It is up to others to consider whether this story from Halls Creek is useful. Guiding principles might be abstracted as:
- Support, resources and funding from the relevant government agency.

- Integration of community values, knowledge and skills.

- Long-term engagement and consultation between key stakeholders.

- Careful translation and negotiation of meaning, knowledge and solutions between the local and state level.

- Local management and ownership.

\section{Connecting Yurag-Man-Gu Taam-Purru to wider issues in Halls Creek}

Along with lobbying in 2006 to address child protection concerns, in 2009 Halls Creek community leaders successfully persuaded the WA government to introduce liquor restrictions (Dyer, 2011). Over a 12 month period reported domestic violence decreased by $25.9 \%$ and alcohol related sexual assaults decreased by $46 \%$ (Kinnane, Golson, HendersonYates, \& Melbourne, 2010).

In all of this there has been a shift in power to the local level as regards community and child well-being. It will be up to a lot of committed people to see such changes are sustained and extended.

\section{Conclusion}

The authors recognise it would be naive to conclude child and family welfare problems at Halls Creek have been resolved because of the initiatives described above. Problems at Halls Creek and in many other communities have arisen for many reasons. Marrying DCP's statutory frameworks together with local approaches was viable as part of an effective response to a dire situation at the time of field research. As a participant concluded: 'Child protection is everyone's business and if we are serious about working with children we need to involve the community and that's what we're aiming to do'.

\section{Acknowledgements}

Thank you to the research participants for sharing your voices and trusting that your narratives would be respected. Thank you to DCP and Curtin University for supporting this research.

\section{References}

Australian Institute of Health and Welfare (2010). Child protection Australia 2008-09. Child welfare series no. 47. Cat. no. CWS 35. Canberra: AIHW.

Australian Institute of Health and Welfare (2012). Child protection Australia 2010-11. Child Welfare series no. 53. Cat. no. CWS 41. Canberra: AIHW. 
Bath, H. (2008). Residential care in Australia, Part 1: Service trends, the young people in care, and needs-based responses, Children Australia 33(2), 6-17.

Bessarab, D., \& Crawford, F. (2013). Trauma, grief and loss: the vulnerability of Aboriginal families in the child protection system in B. Bennett, S. Green, S. Gilbert \& D. Bessarab (eds.). Our Voices: Aboriginal and Torres Strait Islander Social Work, South Yarra: Palgrave Macmillan.

Bhabha, H. K. (1994). The Location of Culture. London: Routledge.

Campbell, D., Wunungmurra, P., \& Nyomba, H. (2010). Starting where the people are: Lessons oncommunity development from a remote Aboriginal Australia setting. Community Development Journal 42(2), 151-166.

Commissioner for Children and Young People Western Australia (2008). Regional Visit Report Halls Creek 23 to 27 June 2008 http://www.ccyp.wa.gov.au/files/Report\% 20-\%20Regional\%20visit\%20Report\%20-\%20Halls\% 20Creek\%202008.pdf

Connolly, M. (2009). The residential practice framework: Integrating research and knowledge with practice. Social Work Now. 43, 12-20.

Council of Australian Governments. (2009). Protecting children is everyone's business: National framework for protecting Australia's children. Canberra: Attorney-General's Department.

Crawford, F. (2011). Local regeneration and social work with Indigenous peoples: The Kimberley across forty years. Australian Social Work, 64(2), 198-214.

Crawford, F., Dudgeon, P., \& Briskman, L. (2007). Developing therapeutic communities for abuse Aboriginal children and their families: An indigenous practitioners' cooperative inquiry. Ministerial Advisory Council on Child Protection \& Curtin University of Technology.

Department of Employment and Workplace Relations. (2006). Halls Creek engagingfamilies trial. February-July 2006: Evaluation report. Department of Employment and Workplace Relations.

Dudgeon, P., \& Fielder, J. (2006). Third spaces within tertiary places: Indigenous Australian studies. Journal of Community and Applied Social Psychology 16, 396-409.

Dyer, N. (2011, October 12). Flight looms over bid to lift grog ban. The West Australian.

Fernandez, E. (2005). Social work in health care settings. In M. Alston, \& J. McKinnon. Social Work: Fields of practice (pp. 190-197). South Melbourne: Oxford University Press.

Gordon, S., Hallahan, K., \& Henry, D. (2002). Putting the picture together: Inquiry into response by government agencies to complaints to family violence and child abuse in Aboriginal communities. West Australian Department of Premier and Cabinet.

Grylls, B. (2006). Halls Creek and Kimberley communities: Establishment of select committee. Western Australian Parliamentary Debates, p787d, 806a.

Halls Creek Community Strategy. (2008). Community action plan: Halls Creek 2008- 2010.
Retrieved from http://avrelay.hcshire.wa.gov.au/ . . /Council\% 20Agenda\%202008.07.17.pdf

Halls Creek Reports Lead to Top Award. (2006, December 2). The West Australian, p. 17.

Higgins, J. R., \& Butler, N. (2007). Indigenous responses to child protection issues: Promising practices in out-of-home care for Aboriginal and Torres Strait Islander carers, children and young people (booklet 4). Melbourne: Australian Institute of Family Studies.

Kimberley Aboriginal Medical Services Council \& WA Country Health Service. (2009). Failure to thrive fact sheet. Retrieved from http://www.kamsc.org.au/documents/ cd_ftt_20_10_08.pdf

Kinnane, S., Golson, K., Henderson-Yates, L., \& Melbourne, J. (2010). An evaluation of the effects of alcohol restrictions in Halls Creek relating to measurable health and social outcomes, community perceptions and alcohol related behaviours after twelve months. Halls Creek Alcohol Restriction Report, West Australian Drug and Alcohol Office.

Libesman, T. (2004). Child welfare approaches for Indigenous communities: International perspectives. National Child Protection Clearing House Issues, 20, 1-39.

Libesman, T. (2007). Indigenising Indigenous Child Welfare. Indigenous Law Bulletin 6 (24), 17-19.

Madison, S. (2008). Narrative poetics and performative interventions. In N. K. Denzin, Y. S. Lincoln., \& L. Tuhiwai., Handbook of Critical and Indigenous Methodologies (pp. 391-405). Thousand Oaks, CA: Sage Publications.

McHale Pledges Support for Halls Creek Hostel (2006, October 7). ABC Premium News, p. 1.

McLean, S., Price-Robertson, R., \& Robinson, E. (2011). Therapeutic residential care in Australia: Taking stock and looking forward. National Child Protection Clearinghouse Issues, $35,2-22$.

Milner, H. (2007). Race, culture, and research positionality: Working through dangers seen, unseen and unforeseen. Educational Researcher 36(7), 388-400. Retrieved from http:// proquest.umi.com.dbgw.lis.curtin.edu.au

Myth of Stolen Generation is Killing Aboriginal Children. (2006, September 7). The Australian, p. 13.

PeakCare Queensland Inc. (2003). The role of residential care in meeting the needs of children and young people in care: A discussion paper. Retrieved from http://peakcare.org.au/ peakcare-position-papers.html

Perry, B. (2001). Bonding and attachment to maltreated children: Consequence of emotional neglect in childhood. Retrieved from http://www.childtrauma.org/ index.php/articles/attachment

Secretariat of National Aboriginal and Islander Child Care (2008). Foster their culture: Caring for Aboriginal and Torres Strait Islander children in out-of-home care. Victoria: Secretariat of National Aboriginal and Islander Child Care. Retrieved from http://www.snaicc. org.au/_uploads/rsfil/02301.pdf 
Stanley, J., Tomison, A. M., \& Pocock, J. (2003). Child abuse and neglect in Indigenous Australian communities. Child abuse prevention issues, (19). Retrieved from www.aifs.org.au/nch/issues/issues19.html

Swain, S., \& Atkinson, S. (1999). A network of support: Mothering across the Koorie community in Victoria, Australia. Women's History Review, 8(2), 219 230 .
Tilbury, C., Osmond, J., Wilson, S., \& Clark, J. (2007). Good Practice in Child Protection. New South Wales: Pearson Education Australia.

Zubryzcki, J., \& Crawford, F. (2013). Collaboration and relationship building in Aboriginal and Torres Strait Islander social work in B. Bennett, S. Green, S. Gilbert \& D. Bessarab (eds) Our Voices: Aboriginal and Torres Strait Islander Social Work, South Yarra: Palgrave Macmillan. 